\title{
CONSTRUINDO ENTENDIMENTOS SOBRE LEITURA E GRAMÁTICA A PARTIR DE UM DIÁLOGO EXPLORATÓRIO COM OS APRENDIZES
}

\author{
Andréia Mello Rangel \\ Mestre em Letras pela Faculdade de Formação de Professores da Universidade do \\ Estado do Rio de Janeiro (FFP/UERJ) \\ profandreiamello@gmail.com \\ Patrícia Graeff Viana Liquieri Ribeiro \\ Mestre em Letras pela Faculdade de Formação de Professores da Universidade do \\ Estado do Rio de Janeiro (FFP/UERJ) \\ pgraeff@gmail.com
}

\section{RESUMO}

Apoiadas na abordagem ético-inclusiva da Prática Exploratória (ALLWRIGHT; HANKS, 2009), apresentamos um recorte da nossa pesquisa, a qual configura um processo de reflexão e de construção de entendimentos sobre nossa vivência profissional como professoras de língua portuguesa e sobre o processo de aprendizagem dos nossos alunos nas aulas de língua materna. Nosso processo de reflexão está baseado na perspectiva sociointeracional da linguagem sustentado pela concepção interacionista. Considerando o fato de que a língua é apreendida na interação (BAKHTIN, 2015), vislumbramos, no contexto de sala de aula, a coconstrução de conhecimentos sobre a língua materna que contemple o uso real e social da língua. Debruçamo-nos, ainda, sobre as práticas de leitura dos aprendizes, no sentido de conhecer tais práticas e, a partir delas, apresentar outras leituras como novas possibilidades, diminuindo, assim, a assimetria entre professor e alunos, tornando o processo de ensinar e de aprender significativo.

Palavras-chave: ensino significativo, língua, leitura, prática exploratória, perspectiva sociointeracional.

\begin{abstract}
Supported in the ethical-inclusive approach of Exploratory Practice (ALLWRIGHT; HANKS, 2009), we present a piece of our research, that configures a process of reflection and development of understandings about our professional experience as Portuguese teachers and about the learning process of our students in their mother language. Our process of reflection is based in the sociointeractional perspective of the language supported by the interactionist conception. Considering the fact that the language is seized in the interaction (BAKHTIN, 2015), we glimpse, in the classroom context, the coconstruction of knowledge about the mother language that contemplates the real and social use of the language. We also lean over the reading practices of the learners, in the sense of knowing such practices and so, present other readings as new possibilities, reducing, thus, the asymmetry between the teacher and the students and making the teaching and learning process expressive.
\end{abstract}

Keywords: expressive teaching, language, reading, exploratory practice, sociointeractional perspective. 


\section{Introdução}

Atuamos como professoras de língua portuguesa em escolas públicas do Estado do Rio de Janeiro e, nesse contexto, deparamo-nos com diversas situações questionadoras quanto ao nosso fazer docente. Neste trabalho, entrelaçamos as nossas experiências como professoras de língua materna a partir, principalmente, do desenvolvimento das pesquisas que coconstruímos com os aprendizes por ocasião dos nossos estudos no mestrado em Letras. Experienciamos um caminho de prática docente por meio da abordagem ético-filosófica da Prática Exploratória (ALLWRIGHT; HANKS, 2009), a qual nos orienta no desenvolvimento de uma aula de língua portuguesa que faça sentido para o aprendiz.

Assim, no primeiro momento deste trabalho, apresentaremos a Prática Exploratória. Em seguida, mostraremos o processo de reflexão sobre as práticas de leitura dos aprendizes, assim como experiências relacionadas ao ensino de gramática. Os aportes teóricos que ancoram o nosso fazer pedagógico, apresentados ao longo deste trabalho, baseiam-se na percepção da língua em uso e no trabalhar para entender.

\section{Prática exploratória: a escuta cuidadosa}

A Prática Exploratória, segundo Dick Allwright, seu idealizador, envolve, sobretudo, um trabalho para entender (ALLWRIGHT; HANKS, 2009). O trabalho para o entendimento surge, então, não para cumprir tópicos pré-determinados, que vêm de fora da sala de aula, sem conhecer a realidade da turma. 
Segundo Moraes Bezerra (2012), ao pesquisador envolvido com a Prática Exploratória não cabe coletar dados e fazer uma análise do corpus de modo a procurar uma verdade absoluta. A Prática Exploratória trabalha a partir de um modelo inclusivo, de forma a envolver todos os participantes da pesquisa na reflexão dos questionamentos levantados e na geração dos possíveis entendimentos provenientes de tais questões (MORAES BEZERRA, ibidem). Não se pretende realizar o que Allwright denomina de pesquisa 'parasítica': "sem contribuir ou, na melhor das hipóteses, com contribuições mínimas ou muito superficiais para o contexto e, principalmente, sem dialogar verdadeiramente com as pessoas 'investigadas'” (MORAES BEZERRA, 2012, p. 60).

Por meio da abordagem da Prática Exploratória, o trabalho para entender desenvolve-se a partir dos porquês a serem respondidos. Esses porquês são questões reflexivas sobre a vida no contexto escolar. Segundo Moraes Bezerra, Miller e Cunha (2007, p. 125), "Puzzle é o nome dado pelos professores, alunos e pesquisadores envolvidos com a Prática Exploratória aos questionamentos trazidos pelos praticantes acerca de questões que os intrigam, preocupam, inquietam." Esse termo é utilizado porque a Prática Exploratória surgiu através do envolvimento de professores de inglês com essa prática reflexiva.

Os puzzles propostos são trabalhados por meio das Atividades Pedagógicas com Potencial Exploratório (APPE). Essas atividades são formas que o professor praticante exploratório possui de planejar o que fará em sala de aula com os alunos a fim de trabalhar para entender os questionamentos que surgem. Essas atividades são, dentro da perspectiva da Prática Exploratória, procedimentos de ensino que o professor cria a fim de focar o trabalho para entender em sua sala de aula ou em sua disciplina. Tais 
atividades são familiares ao professor, porém sofrem alguma modificação para atender ao objetivo da reflexão.

A partir das duas seções seguintes, será possível conhecer um pouco das APPE que construímos ao longo de nosso trabalho para entender com os nossos alunos e com as nossas alunas.

\section{2. "Será que os alunos não leem?" Trabalhando para entender as práticas de leitura dos aprendizes}

Em minha atuação pedagógica, determinadas questões a respeito do trabalho com a leitura e do fomento à formação do leitor sempre me chamaram especial atenção. Dentre essas questões, destaco o distanciamento existente entre a leitura - praticada por muitos de meus alunos (muitas vezes ignorada pela escola) - e o que é apresentado pelos professores para eles como leitura dentro do ambiente escolar.

Quando o assunto é a leitura realizada pelos alunos, a escola - talvez por vincular o ato de ler à variante da língua legitimada e prestigiada socialmente em situações de maior tensão - por meio das falas de diretores, de equipes de articulação pedagógica e de professores, afirma que os alunos não leem ou que leem apenas os pequenos textos que se apresentam para eles, em decorrência do advento da internet, nas plataformas digitais. Dessa forma, os alunos não atenderiam ao objetivo da escola em relação ao que esta entende e legitima como leitura.

Apoiada nos princípios balizadores da Prática Exploratória, os quais me auxiliam no alinhamento do meu fazer docente com a minha atividade de pesquisa, apresento alguns momentos do trabalhar para entender as práticas de leitura dos aprendizes, os quais 
constituem uma turma do nono ano do ensino fundamental, como já apontado, de uma escola pública estadual do Rio de Janeiro. Acredito em uma prática pedagógica baseada no diálogo, na escuta sensível e no olhar atento, os quais são capazes de possibilitar o construir de uma aula de língua portuguesa tecida por educador e educandos.

Nesse sentido, é que se constrói uma tentativa de não fortalecer a distinção entre "currículo formal" e "currículo vivido" (MACEDO, 2006 apud FERRAÇO, 2015, p. 11), mas de entender o currículo como "arena de produção cultural, para além das distinções entre produção e implementação, entre formal e vivido, entre cultura escolar e cultura da escola" (MACEDO, 2006 apud FERRAÇO, 2015, p. 11). Assim, é a própria prática do diálogo - assumida pela abordagem para o ensino e para a pesquisa da Prática Exploratória - o cerne de uma pedagogia crítico-reflexiva, revolucionária e, sobretudo, libertadora, como aponta Freire (1987): “na teoria dialógica a liderança se obriga ao esforço incansável da união dos oprimidos entre si, e deles com ela, para a libertação" (FREIRE, 1987, p. 99).

A atividade de ensino e de pesquisa que coconstruí com os meus alunos ancorou-se também na perspectiva dos Novos Estudos do Letramento [NEL] (STREET, [1984] 2014). Ao reconhecer as práticas de leitura dos meus alunos, eles podem perceber-se como agentes do aprender e, ao mesmo tempo, envolverem-se com outras práticas de letramento, configuradas como oportunidades de acesso a outros bens culturais e a outros espaços sociais. É possível assim não excluir as práticas de letramento, tanto as valorizadas pelos currículos formais, quanto as não valorizadas pelos documentos oficiais curriculares, mas, por meio de um movimento dialógico, torná-las objeto de reflexão, de análise e de crítica. 
A leitura - entendida a partir do modelo interacional de leitura postulado pelo linguista aplicado Moita Lopes (1996) - não configura uma atividade alheia às questões históricas, culturais e sociais imbricadas no texto e na sua construção. O texto medeia a relação autor-leitor que, por sua vez, é atravessada pelos aspectos socioculturais e históricos que os constituem.

Assim, os contextos de produção e de recepção de autor e leitor - distantes espacial e temporalmente - são extremamente relevantes no processo de leitura. Penso que, ao cobrar dos alunos que leiam para cumprir com um objetivo de uma determinada atividade linguística, a escola leva os aprendizes a realizar leituras de modo aligeirado, sem que lhes seja dado o tempo de que muitas vezes precisam para apreciar, compreender, ler criticamente e para se perceberem como agentes desse processo. Diante disso, levantei alguns puzzles sobre aspectos relacionados com a leitura e com o fomento à formação do leitor que me motivam a refletir sobre o que observei no exercício da docência.

Impulsionada pelos puzzles, coconstruí atividades de ensinar-aprender-pesquisar com os meus alunos e com as minhas alunas. Assim, os dados foram gerados a partir de um processo de ensino e aprendizagem exploratório, preconizando o diálogo e buscando considerar as múltiplas epistemes e os diversos letramentos coexistentes no ambiente escolar, de modo a não permitir que apenas os conhecimentos hegemônicos, legitimados nos currículos oficiais, tivessem espaço em sala de aula.

A elaboração das APPE com meus alunos constituiu um grande desafio. Primeiramente porque eles pareciam não entender a importância da participação de todos na elaboração das atividades, embora fossem sempre encorajados a partilharem suas impressões a respeito do que havia sido proposto. Eu buscava vivenciar com eles os 
princípios da Prática Exploratória, em especial, envolvê-los no trabalhar para entender, vivenciando um coleguismo em que a assimetria entre professora e alunos é mitigada.

Construímos coletivamente uma primeira APPE. Inicialmente, poucos aprendizes se manifestavam. Ouviam-se apenas algumas vozes tímidas. No decorrer da coconstrução da atividade, os educandos foram se sentindo mais à vontade para se expressarem e mais acostumados com espaços de escuta sensível de seus anseios e de suas impressões sobre aprendizagem na escola.

No dia em que iniciaríamos, de fato, a realização das atividades coconstruídas por mim e pelos meus alunos, fui surpreendida pela intervenção da maior parte dos aprendizes no trabalho, através da fala da aluna Kelsey (nome fictício indicado pela aluna), a qual representou uma mudança decorrente do processo de construção de autonomia:

Hoje a aluna Kelsey veio me dizer que o assunto de trabalhar com romance surgiu na aula de produção textual e que a professora Cátia queria participar das atividades sobre o gênero romance também. A professora Cátia é fã do autor Nicholas Sparks, e Kelsey perguntou para os demais alunos da turma se eles aceitariam trabalhar com livros desse autor, já que a maioria lia ou já tinha lido um livro escrito por ele. Kelsey disse que a turma tinha concordado e que faltava eu aceitar. Aceitei (Caderno reflexivo da professora, 31 de agosto de 2015).

Surpreendi-me com a forma como Kelsey encaminhou a situação e com os novos contornos que aquelas atividades estavam ganhando e registrei a intervenção da aluna em meu caderno reflexivo (caderno que utilizei para o registro de observações e, sobretudo, de reflexões ao longo da pesquisa). A professora Cátia (nome fictício) e eu não tínhamos muito contato. Os meus alunos, envolvidos como agentes no trabalho para 
entender, estavam provocando a aproximação entre professores, a fim de que o processo de ensino e de aprendizagem fosse favorecido. Eles se percebiam como agentes da aprendizagem, produtores de conhecimento, como Allwright e Hanks (2009) discutem, ao apresentar algumas proposições sobre aprendizes. Certamente, as intervenções feitas por eles mesmos tornavam o processo de ensino e de aprendizagem mais significativo.

Os aprendizes elaboraram pôsteres, os quais constituíram um dos momentos de construção de entendimentos acerca de suas práticas de leitura. Em Prática Exploratória, os praticantes costumam elaborar pôsteres como forma de partilhar seus puzzles e entendimentos. Reserva-se um momento em aula para a produção e, depois, para a apresentação. Assim, a elaboração dos pôsteres, bem como a realização das demais atividades produzidas com os aprendizes, constituíram momentos de reflexão e de aprendizagem colaborativa, provocando, dessa forma, a construção de qualidade de vida dentro do ambiente escolar e acredito que também fora dele, pois os meus alunos e as minhas alunas tiveram reconhecida a sua condição de agentes do processo de aprendizagem.

Ao valorizar o repertório de leitura dos meus alunos, pude me perceber, de fato, como uma professora pesquisadora praticante exploratória, de tal modo que a fala "Nossos alunos não leem", tão comumente escutada nos corredores escolares e entre os professores de língua portuguesa, não ecoou em nossa sala de aula. Pelo contrário, pude ouvir as falas de meus alunos por meio dos nossos momentos de construção colaborativa da APPE e também através de seus pôsteres, os quais apresentavam frases como: "Eu amo ler", "Nós lemos".

Acredito que os diversos contornos que o encaminhamento para o diálogo com as práticas de leitura dos aprendizes ganhou configuram preciosas e ricas possibilidades de 
reflexão para os leitores deste trabalho acerca do realizar políticas em sala de aula para a leitura e, principalmente, com a leitura. O fio condutor da Prática Exploratória - convite a caminhos de reflexão e ao constante agir para entender - permanece neste trabalho para mim, para os meus alunos, para os leitores destas linhas.

Esse permanecer se concretizou, em minha relação com os meus alunos da turma 905, na construção, por parte dos meus alunos, de um grupo no aplicativo de mensagens instantâneas whatsapp. Era o mês de junho de dois mil e dezesseis e eu já não mais atuava como professora daqueles meninos e daquelas meninas. Senti-me feliz com a criação do grupo e aproveitei a oportunidade para explicar para os meus queridos e para as minhas queridas da turma 905/2015 que eu estava na fase de escrita do trabalho de pesquisa do mestrado. Pudemos conversar um pouco mais sobre os entendimentos do que foi o nosso processo de investigação exploratória a respeito de suas práticas de leitura. Pedi para que os alunos que se sentissem à vontade gravassem um áudio e/ou enviassem para mim um texto escrito, no qual dissessem um pouco sobre como, após o término da atividade, viam aquela nossa vivência de investigação exploratória. Pedi, também, para que a professora Cátia se manifestasse nesse sentido.

Foi lindo ouvir o aluno Naruto (nome fictício indicado pelo aluno) dizer: "Eu gostei muito da atividade, porque ela envolvia os livros que a gente lia no cotidiano e nunca um professor perguntou isso para os alunos, pelo menos pra minha turma, que sempre foi a mesma turma. Foi bom, porque uniu muito a turma também".

"A gente mal se falava. Mas nem era por maldade (risos). É porque os nossos estilos de vida são diferentes (...). Mas a grande surpresa da vida, a grande coisa foi que o que nos uniu foram, justamente, as nossas diferenças. Foi isso que nos uniu. Na hora que a gente foi trabalhar o romance, quando a gente sentou pra dividir, pra ver o que ia fazer, 
você tinha a parte teórica e eu tinha a experiência dos livros que os alunos queriam (risos). Então foram justamente as nossas diferenças que foi (...) a grande coisa disso tudo!" Cátia contribuiu com essa fala linda, lúcida, generosa. Ao terminar de escutar o áudio que ela havia me enviado, confesso que fiquei bastante emocionada.

Em um mundo onde as pessoas parecem estar construindo cada vez mais muros de intolerância, de desrespeito e de desamor, Cátia falou de diferenças que não criam linhas abissais, mas que constroem pontes; de diferenças capazes de unir, de promoverem a escuta sensível, o olhar atento; de diferenças capazes de construírem o diálogo.

É possível que sejam levantadas críticas a essa experiência e ao fato de os alunos colocarem-se como leitores, alegando-se que eles apenas disseram o que a professora desejava ouvir. Contraponho a essa fala o fato de havermos partido dos seus interesses de leitura, valorizando os livros que vinham para a sala de aula, mas que permaneciam nas mochilas porque não havia lugar para eles no conteúdo oficial. Na medida em que se abriu espaço para as vozes desses autores, entrelaçadas às vozes dos alunos, ao entendermos que "outras literaturas" também são fonte de leitura, pudemos redimensionar o gostar de ler. Esse movimento, de forma alguma invalida o diálogo com o cânone, como privilegiado pelo currículo. No entanto, pluraliza e enriquece a experiência de leitura que se faz em sala de aula.

\section{Escolhas discursivas: coconstruindo um ensino significativo da língua portuguesa}

Na busca de entendimentos sobre um ensino significativo a partir da ideia de língua como prática social, desenvolvo um trabalho voltado para a produção de sentido. Procuro 
potencializar a participação dos aprendizes, uma vez que estes ainda estão inseridos em um trabalho com a língua que, muitas vezes, focaliza a forma em detrimento de uma prática balizada nos gêneros discursivos. Considero desafiador, como lembra Geraldi (2013), ensinar uma língua a pessoas que já a dominam de forma a se expressarem no dia a dia.

Considerando a visão do discurso como uma maneira de coparticipação social (MOITA LOPES, 2002), entendo que os significados são coconstruídos pelos participantes dentro do discurso. Assim, ratifica-se a necessidade de uma participação ativa dos aprendizes na construção de sua própria aprendizagem. Nesse sentido, é mister considerar o aprendiz, assim como qualquer sujeito, como alguém historicamente situado e possuidor de conhecimento de mundo, que, por sua vez, não pode ser ignorado pelo professor. Para isso, por meio de um viés vygotskyano, compreendo que a minha postura enquanto professora é de mediadora no desenvolvimento do processo de coconstrução de sentidos sobre a língua em uso.

Entender qual é o objetivo de nossas aulas de língua portuguesa é imprescindível para que construamos um caminho coerente. Para tanto, acredito que desenvolver e ampliar a competência discursiva de nossos alunos seja o foco das aulas.

Realizar um trabalho significativo com a língua materna compreende interação autêntica (NEVES, 2014). Faz-se necessário estar atento às situações de sala de aula que propiciam uma verdadeira interação com os aprendizes de modo que a situação interativa surja da própria atividade de fala, não sendo, portanto, artificial (NEVES, 2014) e, configurando, assim, a língua em uso. Faz-se necessário perceber o discurso como construção social (MOITA LOPES, 2002), ou seja, como uma forma de agir no mundo. 
Levando em consideração essa perspectiva, é possível afirmar que os aprendizes, por meio da linguagem, agem no mundo, posicionando-se, construindo suas opiniões.

Neves (2014) preconiza que o trabalho com a gramática deve ser desenvolvido pelo viés da reflexão sobre o funcionamento da linguagem, pois dessa forma, estar-se-á posicionando a gramática a serviço da língua em uso. Vale ressaltar que tal ensino não exclui as regras abordadas pela gramática normativa, visto que esse entendimento pode possuir potencial significativo para a vida dos estudantes se levarmos em consideração o acesso a postos de trabalho, a concursos para carreiras públicas, enfim todo um universo de possibilidades do qual o aprendiz pode participar e ser cobrado quanto à forma em detrimento das reflexões a respeito da língua em uso. O impasse consiste em "como" desenvolver um trabalho que propicie o ensino da norma culta como mais uma modalidade a que o aprendiz pode ter acesso e como refletir, efetivamente, sobre as escolhas discursivas dos falantes, visto que elas não são aleatórias, e, portanto, tais escolhas são importantes para o sentido da enunciação.

Analiso a seguir uma questão e as respostas fornecidas pelos alunos, as quais fizeram parte de uma APPE construída com uma turma de ensino médio. Ressalto que os nomes dos alunos são fictícios.

POR EDITORIAL - 31/07/2016 0:00

A acertada suspensão do ciência sem fronteira

A tendência do político é considerar intocáveis os gastos ditos sociais. 0 país é considerado de renda média, mas há grandes contingentes de eleitores pobres, sempre cortejados dos palanques. Porém, existem limites. 0 principal deles, a disponibilidade de dinheiro público. Quando ele escasseia, como agora, mesmo que não se queira é preciso fazer escolhas, seguir critérios. A alternativa é agravar o desequilíbrio nas contas públicas até a debacle da recessão profunda e da hiperinflação.

$\mathrm{O}$ governo do presidente interino Michel Temer tem mesmo de avaliar cada programa social. Até por uma fé ideológica tosca na ideia de que tudo que 
for feito em nome do pobre é válido - inclusive exercitar a corrupção -, petistas relaxaram na supervisão, avaliação e controle das bilionárias despesas sociais.

O Bolsa Família, não se discute que deva ser mantido. Mas sabe-se que auditorias pouco extensas têm encontrado desvios graves, como mortos inscritos no programa.

Ao avaliar o programa Ciência sem Fronteira (CSF), o Ministério da Educação concluiu que o melhor é cortá-lo, não conceder mais bolsas de estudo no exterior - sempre alardeadas na programação eleitoral da presidente Dilma Rousseff como a redenção do jovem pobre.

Numa avaliação fria, na conjuntura por que se passa de penúria na Educação, o governo acerta, e nisso tem o apoio na academia. Por exemplo, da presidente da Sociedade Brasileira para o Progresso da Ciência (SBPC), Helena Nader. Ela entende, com razão, que, no momento, é melhor destinar recursos para programas de iniciação científica já existentes e que estão em dificuldade.

Não faz mesmo sentido mandar jovens para o exterior enquanto laboratórios e cursos de pós-graduação nas universidades brasileiras são sucateados e ficam à míngua. O sociólogo Simon Schwartzman, especialista em Educação, ex-presidente do IBGE, acha que o CsF não justificava o custo. De fato.

A partir de 2011, início do programa, foram gastos nele $\mathrm{R} \$ 8,4$ bilhões, na concessão de mais de 100 mil bolsas para graduação e pós, em universidades de 54 países. Segundo o ministro da Educação, Mendonça Filho, cada aluno custou por ano R\$ 105 mil.

Já Antônio Freitas, da Academia Brasileira de Educação, diz que a maioria dos estudantes foi para universidades medianas, enquanto excelentes laboratórios da UFRJ estão sem recursos. Um raciocínio lógico simples conclui que o governo tomou a melhor decisão. É certo que haverá críticas, principalmente do campo lulopetista. Mas a lição que fica da ascensão e queda do CsF é que gastar o dinheiro do contribuinte de forma populista, sem preocupações maiores com a avaliação dos programas, é contraproducente até para os beneficiários. Depois, o mercado de trabalho é que tratará de punir os mal qualificados. Mas aí o dinheiro público já se perdeu.

Fonte: Disponível em: <http://oglobo.globo.com/opiniao/a-acertada-suspensao-do-ciencia-sem-fronteira19812934>. Acesso em: 16 set. 2016.

\section{A partir do título do texto, pode-se entender que o autor concorda ou não com a decisão do governo de acabar com o programa? Justifique sua resposta.}

Mari: Sim, acho que concordou pelo simples fato de ter usado a palavra "acertada", acho que se o autor usou essa palavra ele concorda com a suspensão do projeto. Se não concordasse, na minha opinião, colocaria "A errada suspensão do ciência sem fronteiras".

Biel: Pode-se entender que sim, pois quando ele diz "A Acertada", ele está falando de forma em que confirma a ideia dita. 
Tom: Com base no texto, podemos afirmar que sim. $\mathrm{O}$ autor do texto de fato concorda com o programa, pois são muitos gastos.

Raí: Sim, porque ele não aceita que paguem uma fortuna para alunos estudarem no exterior. E aqui no Brasil, não ter recursos.

Dado: Ele não concorda, porque no parágrafo sete ele diz uma coisa importante pra mim: não faz sentido mandar jovens para o exterior enquanto laboratórios e cursos de pós-graduação nas universidades brasileiras são sucateados e ficam à mingua.

Duda: O autor concorda, pois em toda a parte do texto ele fala que foi melhor pois os laboratórios e universidades do país estavam ficando jogados enquanto ele pegava esse dinheiro para levar alunos para outro lugar, pois se ele não levar o aluno para fora e investir nas universidades daqui do país, os alunos aprenderão mais sem ficar longe da família.

Nas respostas de Mari e Biel há a ideia de que o autor concorda com a medida do governo, justificada a partir do vocábulo do título, de modo que Mari, inclusive, escreve além do solicitado, ao afirmar qual poderia ser a escolha discursiva do enunciador caso ele não concordasse com o projeto do governo, alterando o enunciado para: "A errada decisão". Outros alunos explicam a posição do enunciador na argumentação não a partir do título, mas por meio do contexto em si, como mostrou Tom e Raí. A Duda também traz justificativas de maneira a considerar o contexto, no entanto, ela também parece incorporar à argumentação do autor o seu próprio pensamento, uma vez que declara que, ao investir nas universidades brasileiras, o governo permite que os alunos aprendam sem que com isso eles tenham de ficar longe de seus pais. Esse final da justificativa da Duda marca sua posição na argumentação, ratificando uma opinião nas discussões em sala em que sempre demonstrava seu pensamento a favor das providências anunciadas pelo até então presidente interino. Já a resposta de Dado pareceu confusa, pois ele afirmou que o autor não concorda com a decisão do governo, entretanto, apresentou um exemplo que vai de encontro à sua resposta. Além disso, o aluno deixa transparecer que a argumentação que fez o autor do texto, convenceu-o. Afirmo isso porque Dado iniciou 
sua justificativa escrevendo que, para ele, "não fazia sentido", ou seja, demonstrando sua concordância com o argumento que trouxe o enunciador do texto.

Acredito que com esse tipo de reflexão colabora para que o aluno possa pensar sobre o mundo, não limitando o ensino a uma metalinguagem ou a uma reflexão sobre a língua desvinculada do contexto sócio-histórico. Faltar com esse tipo de discussão em sala de aula seria tomar um posicionamento elitista, uma vez que delimita o conhecimento das coisas ao privilégio das elites (FREIRE, 2015). A terceira concepção da linguagem apresentada por Travaglia (2009) justifica expor os alunos a esse tipo de atividade, visto que evidencia o contexto sócio-histórico-ideológico que não pode ser negligenciado sob pena de o professor promover um ensino alienante.

Perceber as escolhas discursivas que estão presentes nos textos, como a expressão "acertada decisão", permite também pensar de que lugar social fala aquele que produz tal enunciado, e um estudo significativo da língua precisa promover essas reflexões. Segundo Geraldi (2011, p. 42), “estudar a língua é, então, tentar detectar os compromissos que se criam por meio da fala e as condições que devem ser preenchidas por um falante para falar de certa forma em determinada situação concreta de interação". Considerando, portanto, que o enunciado reflete sempre o processo de um discurso (BAKHTIN, [1979] 2015), é importante que o professor atente os alunos para as escolhas discursivas de um texto, colaborando para que o aluno reflita sobre a questão.

\section{Considerações finais}

Escrevemos as últimas linhas deste trabalho impulsionadas pelo fio condutor da Prática Exploratória, o qual nos convida à contínua construção de caminhos de reflexão e 
ao constante agir para entender. Entender a língua como um meio de constituição das relações sociais (GERALDI, 2011) ressignifica a prática de qualquer professor da área de linguagens. Apresentamos, neste artigo, possibilidades de coconstruir entendimentos sobre leitura e sobre gramática. Essas possibilidades foram balizadas no diálogo exploratório e no reconhecimento da agência dos aprendizes no processo de ensinar e de aprender. Portanto, faz-se necessário pensar sobre um fazer pedagógico que valorize o humano, a criatividade, a reflexão, o diálogo e a expressão de ideias.

\section{Referências}

ALLWRIGHT, D. et al. From teaching points to learning opportunities and beyond. Tesol Quarterly, Lancaster, mar. 2005.

ALLWRIGHT, D.; HANKS, J. The Developing language learner: an introduction to exploratory practice. London: Palgrave Macmillan, 2009.

ALLWRIGHT, D. Entrevista. Jornal da PUC-Rio, Ed. Projeto Comunicar, 2010.

BAKHTIN M. Os gêneros do discurso. In: Estética da criação verbal. São Paulo: Martins Fontes, 2015. p. 261-306.

FERRAÇO, C. E. Currículo, cotidiano escolar e conhecimentos em redes. In: Pacto Nacional pela Alfabetização na Idade Certa. Currículo na perspectiva da inclusão e da diversidade: as diretrizes Curriculares Nacionais da Educação Básica e o ciclo de alfabetização. Caderno 1. Ministério da Educação, Secretaria de Educação Básica, Diretoria de Apoio à gestão Educacional. Brasília: MEC, SEB, 2015.

FREIRE, P. Pedagogia do oprimido. 17 ed. Rio de Janeiro: Paz e Terra, 1987. GERALDI, J. W. Portos de passagem. 5 ed. São Paulo: Martins Fontes, 2013. MOITA LOPES, L. P. Oficina de linguística aplicada: a natureza social e educacional dos processos de ensino/aprendizagem de línguas. São Paulo: Mercado de Letras, 1996. 
MORAES BeZERRA, I. C. R.; MILLER, I. K.; CUNHA, M. I. A. Prática de ensino e prática exploratória: oportunidades para buscar compreender a vida no cotidiano escolar. In: FONTOURA, Helena Amaral da (Org.). Diálogos em formação de professores: pesquisas e práticas, Niterói: Intertexto, 2007. p. 60-77.

MORAES BEZERRA, I. C. R. Prática exploratória e a formação inicial do professor reflexivo: “O que vai ficar para os alunos?". In: Revista Contemporânea de Educação. Rio de Janeiro, v. 7, n. 13, jan/jul, p. 60-77, 2012.

NEVES, M. H. M. Que gramática estudar na escola? Norma e uso na língua portuguesa. 4 ed. São Paulo: Contexto, 2014.

STREET, B. V. Letramentos sociais: abordagens críticas do letramento no desenvolvimento, na etnografia e na educação. Tradução de Marcos Bagno. São Paulo: Parábola, 2014.

TRAVAGLIA, L. C. Gramática e interação: uma proposta para o ensino de gramática. 14 ed. São Paulo: Cortez, 2009.

Recebido em 16 de março de 2018.

Aceito em 16 de abril de 2018. 